\title{
EXPERIMENTAL AND NUMERICAL INVESTIGATION OF EFFECT OF BLOWING RATIO ON FILM COOLING EFFECTIVENESS AND HEAT TRANSFER COEFFICIENT OVER A GAS TURBINE BLADE LEADING EDGE FILM COOLING CONFIGURATIONS.
}

\author{
Giridhara Babu Yepuri \\ Senior Scientist, Heat Transfer Lab \\ Propulsion Division, CSIR-NAL \\ Bangalore, Karnataka, India. \\ giris@nal.res.in \\ Felix Jesuraj \\ Scientist, Propulsion Division \\ CSIR-NAL, Bangalore \\ Karnataka, India. \\ felix@nal.res.in
}

\author{
Gururaj Lalgi \\ Siddaganga Institute of \\ Technology, \\ Tumkur, Karnataka, India. \\ gururaj.lalgi@gmail.com
Sreenivas Rao V. Kenkere
Professor, Siddaganga
Institute of Technology
Tumkur, Karnataka, India.
kvsreenivasarao@yahoo.com

\author{
Ashok Babu Talanki Puttarangasetty \\ Professor, NITK \\ Surathkal, Mangalore \\ Karnataka, India. \\ tpashok@gmail.com
}

\author{
Vinod kumar Nanjundaiah \\ Scientist, Propulsion Division \\ CSIR-NAL, Bangalore Karnataka, \\ India. \\ nvkumar@nal.res.in
}

\begin{abstract}
Film cooling is one of the cooling techniques to cool the hot section components of a gas turbine engines. The gas turbine blade leading edges are the vital parts in the turbines as they are directly hit by the hot gases, hence the optimized cooling of gas turbine blade surfaces is essential. This study aims at investigating the film cooling effectiveness and heat transfer coefficient experimentally and numerically for the three different gas turbine blade leading edge models each having the one row of film cooling holes at 15, 30 and 45 degrees hole orientation angle respectively from stagnation line. Each row has the five holes with the hole diameter of $3 \mathrm{~mm}$, pitch of $20 \mathrm{~mm}$ and has the hole inclination angle of 20deg. in spanwise direction. Experiments are carried out using the subsonic cascade tunnel facility of National Aerospace Laboratories, Bangalore at a nominal flow Reynolds number of 1,00,000 based on the leading edge diameter, varying the blowing ratios of 1.2, 1.50, 1.75 and 2.0. In addition, an attempt has been made for the film cooling effectiveness using CFD simulation, using $k$-€ realizable turbulence model to solve the flow field. Among the considered 15, 30 and 45 deg. models, both the cooling effectiveness and heat transfer coefficient shown the increase with the increase in hole orientation angle from stagnation line. The film cooling effectiveness increases with the increase in blowing ratio upto 1.5 for the 15 and $30 \mathrm{deg}$. models, whereas on the 45 deg. model the increase in effectiveness shown upto the blowing ratio of 1.75 . The heat transfer coefficient values showed the increase with the increase in blowing ratio for all the considered three models. The CFD results in the form of temperature, velocity contours
\end{abstract}

and film cooling effectiveness values have shown the meaningful results with the experimental values.

\section{INTRODUCTION}

In today's modern world, the gas turbines operate at higher gas temperatures in the range of 1800-2000 Degree Celsius in different applications like aircraft and land based power plants. In other side the thermal efficiency and power output of gas turbine increases with increasing turbine rotor inlet temperatures (RIT). Clearly, increasing rotor inlet temperature is one of the key technologies in raising gas turbine engine performance. At these higher temperatures, blade materials may start to melt or high thermal stresses may occur. Hence to with stand these higher rotor inlet temperatures to have higher thermal efficiencies, the gas turbine blades need an optimized cooling without compromising on the engine efficiency.

Shuye Tenge et al. [1] studied three types of hole geometries i.e. cylindrical hole, fan shaped hole and laid back fan shaped hole. They have shown that expanded holes i.e. the fan shaped holes and laid back fan shaped holes show significantly improved thermal protection of the surface downstream of the ejection location as compared to the cylindrical holes. The hole geometries used in the experiments have the film holes of $1.905 \mathrm{~mm}$ and $10.16 \mathrm{~mm}$ apart from one another with a $\mathrm{p} / \mathrm{d}$ of 5.3 , have a radial angle of $90 \mathrm{deg}$. and a tangential angle of 40 deg. The film hole length is $15 \mathrm{~mm}$. For the fan shaped and laid back shaped hole, the calculation of the blowing ratio was based on the inlet cross sectional area of these film cooling holes. Hence, in this study, by using the same blowing ratio for all the models, the shaped hole can be directly compared to those of 
the cylindrical hole, which makes it more convenient to evaluate the effect of hole shape. These experiments performed at a cascade exit Reynolds no. of $5.3 \times 10^{5}$ The corresponding flow velocity at the exit was $50 \mathrm{~m} / \mathrm{s}$, air as coolant was used at blowing ratios of $0.4,0.6,0.8$, and 1.2 with the no rod and no wake cases and with wake cases. Ken-ichi Funazaki et al. [2] studied the effect of free stream turbulence on leading edge film cooling and they calculated heat transfer coefficient and adiabatic film effectiveness. The study examines several test cases with the different blowing ratios at three mainstream turbulence intensities using two types of leading edge models with cylindrical holes and diffuser holes. Their result shows that in case of diffuser hole, the effect of mainstream turbulence intensity appears significantly and spanwise averaged film effectiveness is decreased. In their CFD approach, Time averaged Reynolds-Averaged Navier-Stokes (RANS) approach using Shear-Stress Transport (SST) two-equation model was employed.

May Kyu Kyu Soe et al. [3], Anti vortex film cooling concept is designed to mitigate the effects of the counter rotating vortex pair, which reduces the effectiveness of circular cross section film cooling holes at moderate to high blowing ratios. The 3D computational geometries are modeled with a single 30 degree angled hole on a flat surface. Numerical simulations have been performed at six different coolants to mainstream blowing ratios and used five different turbulence models. In their study, main film hole diameter is $4 \mathrm{~mm}$, inclination angle is set at $30 \mathrm{deg}$. The side holes are $3 \mathrm{~mm}$ diameter in each and angled 9 deg. spanwise direction from centerline of main hole axis. ANSYS ICEM CFD was used to create a computational grid. The tetra mesh was constructed for whole domain. The Preprocessor, solver, and Postprocessor modules are employed by ANSYS CFX. Air ideal gas is used as coolant and mainstream. Result shows that lateral spreading and spanwise effectiveness of baseline cylindrical hole are decreased by increasing the blowing ratio because of jet penetration to the main stream. The spanwise effectiveness of antivortex hole is high obviously in all blowing ratios due to the interaction of side hole vortices leads to reduce the main hole vorticity. Antivortex hole have better efficiency than base line. The better spreading of the cooling film and spanwise averaged effectiveness compared to the other holes. James L. Rutledge et al. [4], studied CFD predictions of pulsed film cooling heat flux on a turbine blade leading edge. A computational study was conducted to determine how leading edge film cooling performance is affected by pulsing the coolant flow. A cylindrical leading edge with a flat after body is used to simulate the turbine blade leading edge region. A single coolant hole was located $21.5 \mathrm{deg}$. from the leading edge stagnation line, angled $20 \mathrm{deg}$. to the surface and 90 degree from the streamwise direction.

Jc Chin Han and Srinath Ekkad[5], Film cooling is the introduction of a secondary fluid at one or more discrete locations along a surface exposed to a high temperature environment to protect that surface not only in the immediate region of injection but also in the downstream region. Turbine airfoil surfaces, shrouds, blades tips and end walls are cooled by using this type of discrete hole film cooling. Film cooling protects the airfoil surface directly, compared to internal cooling technique that remove heat from the inside surface. Film cooling also removes heat from the blade surface through the film hole by internal convection. The thermal protection is expected to provide reduced heat load to the airfoil surface. Designers need to know the net heat load into the component surface when film is injected. Due to complex nature of discrete hole injection, there is need to know the local wall temperature $\left(T_{w}\right)$ under the film and the gas side heat transfer coefficient with film injection. Both these components are required to estimate reduced heat load to the surface.

Hence, Film cooling is primarily depends on the coolant to hot mainstream pressure ratio $(\mathrm{Pc} / \mathrm{Pt})$, temperature ratio $(\mathrm{Tc} / \mathrm{Tg})$, the film cooling hole location, configuration and distribution on a film cooled airfoil. The coolant-to-mainstream pressure ratio can be related to the coolant-to-mainstream mass flux ratio (i.e. blowing ratio) the coolant-to mainstream temperature ratio can be related to the coolant-to-mainstream density ratio. In a typical gas turbine airfoil, the $\mathrm{Pc} / \mathrm{Pt}$ ratios vary from 1.02 to 1.10 , corresponding blowing ratios approximately from 0.5 to 2.0 while the $\mathrm{Tc} / \mathrm{Tg}$ values vary from 0.5 to 0.85 , corresponding density ratios approximately from 2.0 to 1.15 .

From the above detailed literature survey, we found the optimization of turbine blade leading edge film cooling requires the investigation of various flow and geometrical conditions like hole shape, hole location, diameter of the hole, hole angle with respect to leading edge surface, coolant to mainstream blowing ratio (B.R) and density ratio (D.R). Amongst them blowing ratio has significant effect on the film cooling effectiveness, heat transfer coefficient and controlling the bleed air from the compressor.

The present study is mainly focused on the effect of blowing ratio and hole location on the adiabatic film cooling effectiveness over the gas turbine blade leading edge configurations both experimentally and numerically. Under this study, the three models with the row of five holes at 15,30 and 45 degree locations from the stagnation line are considered. These models are tested to find the adiabatic film cooling effectiveness at a density ratio of 1.25 with the coolant to mainstream blowing ratios of $1.25,1.50,1.75$ and 2.0 at a nominal flow Reynolds number of 1,00,000 considered based on the leading edge diameter.

\section{EXPERIMENTAL SETUP AND PROCEDURE 2.1 Model Description}

Semicircular leading edge models are prepared with a low thermal conductivity material to avoid heat losses from the gas path noncontact side of the model and these models are prepared by Rapid proto typing method with SLS process. The material used for model is Nylon having a low thermal conductivity of $0.25 \mathrm{~W} / \mathrm{mK}$ which can be withstand upto 140 degree Celsius. 


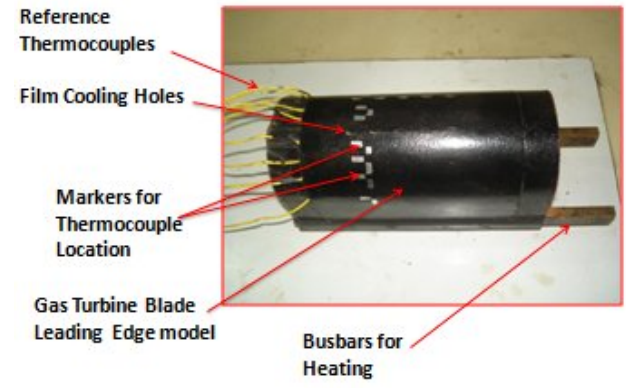

Figure 1: Fabricated turbine blade leading edge model with the row of holes at 15 degrees from the stagnation line.

The test models are prepared half cylindrical with flat downstream surfaces by attaching the coolant chamber. Models are prepared with an outer diameter of $90 \mathrm{~mm}$ and inner diameter of $70 \mathrm{~mm}$ with the film holes of $3 \mathrm{~mm}$ diameter at 20 deg. spanwise inclination angle of the film hole. The total model height is taken as $210 \mathrm{~mm}$ with the row of five holes at $20 \mathrm{~mm}$ pitch with the hole orientation angles of 15,30 and 45 degrees from the stagnation line respectively for the three models. Hard foam is filled in the model slots to have the further low thermal conductivity. The Fig.1 shows fabricated model of turbine blade leading edge scaled up configuration. Stainless steel sheet having thickness of $0.15 \mathrm{~mm}$ with a required film cooling hole geometry, machined by water jet cutting is wound over the model. The SS sheet with an area of $220 \mathrm{x}$ $160 \mathrm{~mm}$ is connected in series by brass bus bars to supply the high current at low voltage to heat the model. The reference thermocouples are soldered underside of the SS sheet for applying the correction factor to the thermogram data and these are routed through the model slots.

The Fig. 2 shows gas turbine leading edge models with the row of coolant holes at the hole orientation angles of 15, 30 and 45 degrees from stagnation line respectively and the models are prepared to withstand the experimental conditions.
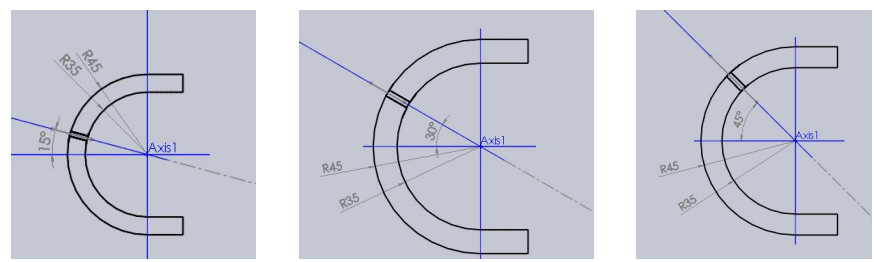

Figure 2: Blade leading edge models with the row of cooling holes at 15,30 and $45 \mathrm{deg}$. from the stagnation line.

\subsection{Experimental Setup}

Gas turbine leading edge model is mounted in the test module; consisting of machined rectangular duct with a size of $330 \mathrm{~mm} \mathrm{x}$ $210 \mathrm{~mm} \times 700 \mathrm{~mm}$. Experimental test facility consists of compressed air unit, settling chamber, air filter, control valve, orifice meter and rectangular duct where gas turbine leading edge models are placed. Air is selected as working fluid for both mainstream and coolant. Main stream flows through the settling chamber to the test section. The main flow is controlled by the gate valve placed much ahead of settling chamber. The coolant air to the model is passed through the heat exchanger, where the controlled liquid nitrogen is used cool the coolant air to have the required coolant temperature. The static and total pressures of mainstream flow to the inlet of test section are measured and maintained to have the required Reynolds number. The coolant flow passing through the orifice meter is also maintained by monitoring the upstream and differential pressures across the orifice meter. The required coolant flow is maintained to have the blowing ratios of $1.25,1.50,1.75$ and 2.0. The mainstream and coolant temperatures are monitored and maintained to have the required density ratio. To measure the pressure and temperature of main stream and coolant air, pressure ports and thermocouples are incorporated at inlet and outlet of rectangular duct and inlet coolant chamber. Flir make Infra red Camera is used for the non contact type temperature measurement of the test surface. The calibrated reference thermocouples are placed on the test model to correct thermo gram test surface data obtained by the Infra red camera. Pressure net scanner is used for measuring pressures from pressure ports and the Fluke data acquisition is used to measure the temperatures of thermocouples.

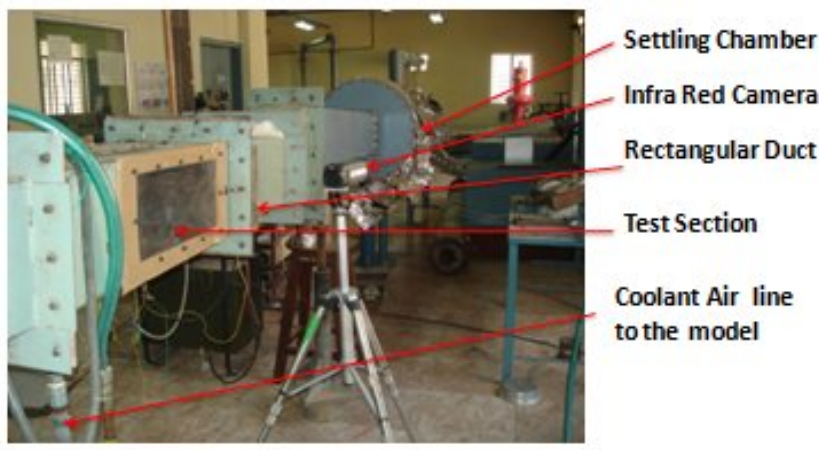

Figure 3: Experimental test setup

The Fig.3 shows experimental setup with data acquisition system. For these experiments, the air is drawn from the centralized air compressor facility of NAL, with the continuous pressure of $40 \mathrm{psi}$. The gate valve is used to maintain experimental pressure at the inlet to the test rig. The rectangular test section is fully tightened to withstand with high pressure. Fig. 4 shows the model mounted in test setup. The test section is made with large opening to view the model by infrared camera through transparent sheet and also the provision is made for coolant air supply to the cooling chamber. 


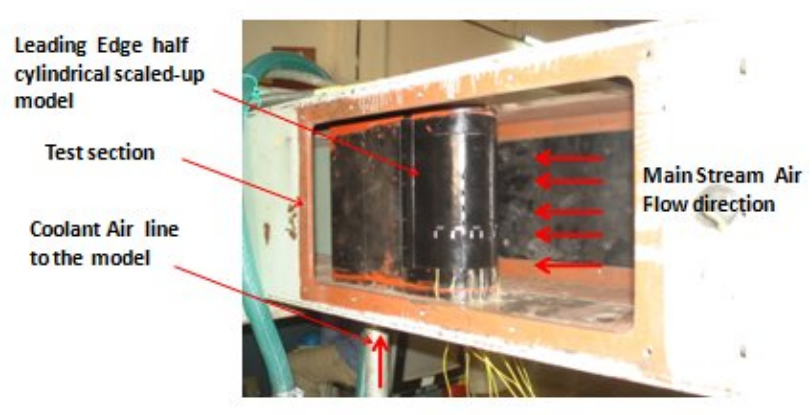

Figure 4: Test model mounted in the test section.

\section{EXPERIMENTAL PROCEDURE}

From the adiabatic wall effectiveness approach, the film effectiveness and the heat transfer coefficient are determined with the two separate experiments. For a Steady state flow, both the main stream and the coolant fluids have been allowed to flow with a required constant velocities and temperatures respectively for 10 minutes before taking the each set of readings at the respective blowing ratios.

\subsection{Film Cooling Effectiveness Measurement}

In film cooling experiments, the main stream air is allowed to flow over the test surface and the coolant flow is passed through the coolant chamber, which ejects through the film cooling holes. The required coolant flow is maintained to have the blowing ratios i.e. the coolant to main stream mass flux ratio of $1.25,1.50,1.75$ and 2.0. The coolant temperature is maintained at $243 \mathrm{~K}$ by controlled liquid nitrogen flow to the heat exchanger to have the required density ratio i.e. the coolant to main stream density ratio of 1.25 . The main stream air at ambient temperature coming from the centralized compressor facility is maintained at $24 \mathrm{~mm}$ of $\mathrm{H}_{2} \mathrm{O}$ to have the Reynolds number of 100000 based on the leading edge diameter.

The wall temperature is measured using non contact type infra red camera after the steady state main stream and coolant flows have been achieved. The film effectiveness measurements are made with the mainstream at ambient temperature, coolant temp and with the wall temperature measured as adiabatic wall temperature, as the surface is unheated and well insulated. The local wall temperature is mixture temperature of the coolant and mainstream. Thus, the film effectiveness is found using the following relation.

$$
\text { Film Cooling Effectiveness, } 1=\frac{\left(T_{m}-T_{w}\right)}{\left(T_{m}-T_{c}\right)}
$$

\subsection{Heat Transfer Coefficient Measurement}

The heat transfer coefficient is measured with mainstream and coolant air at the same temperature, which is ambient temperature and the test surface is heated. The test plate is typically made of low conducting material to avoid heat losses from the gas path noncontact side of the model. The test surface is connected in series by brass bus bars to supply the required current at low voltage for uniform heating the test surface. The test surface when heated, serves as a constant heat flux surface for the heat transfer tests. The conduction loss data is estimated by the conduction loss experiments. The total input electrical power is calculated by measuring the voltage and current values. The net heat input to the test surface is calculated by subtracting the conduction losses from the input electrical power. Here, the input electrical power and the conduction losses are calculated per unit surface area of test plate. Hence, the calculated net heat flux, $\mathrm{q}$ is the net heat input per unit surface area of the test plate. The heated surface exposed to the main stream and the required coolant with the suitable blowing ratio. After achieving the steady state, the surface temperature data is captured by the infra red camera thermo graphic image. The wall temperature is extracted from the thermo graphic image data, the main stream temperature is measured by thermocouples.

Heat transfer coefficient is calculated by using the following relation for all the models at the blowing ratios of $1.25,1.50$, 1.75 and 2.0. Here, the heat transfer coefficient (h) is calculated from the net heat flux, $\mathrm{q}=\mathrm{Q} / \mathrm{A}$ i.e the net heat input per unit surface area of the plate.

$$
\begin{aligned}
& \text { Net Heat Input, Q = hADT = Qgen }- \text { Qloss } \\
& \text { Net Heat Flux, } \mathrm{q}=\frac{\mathrm{Q}}{\mathrm{A}}=\frac{\mathrm{Qgen}_{\mathrm{gen}}}{\mathrm{A}}-\frac{\mathrm{Q}_{\mathrm{los}}}{\mathrm{A}} \\
& \text { Heal Trans[er Cueflicienl, } h-\frac{q}{\left(T_{w}-T_{m}\right)}-\frac{q_{g m}-q_{\text {lon }}}{\left(T_{w}-T_{m}\right)}
\end{aligned}
$$

To establish repeatability, experiments are conducted at least three times on each hole configuration of 15,30 and $45 \mathrm{deg}$. coolant hole models at one blowing ratio. The error analysis based on an absolute temperature error of $0.1^{\circ} \mathrm{C}$ and the pressure variation with $\pm 0.025 \%$, yields an average relative error of approximately $6 \%$ on heat transfer coefficient and $5 \%$ on adiabatic film cooling effectiveness. All the instruments used in the experiments are calibrated with the standard calibrating primary and secondary sources. Pressure net scanner is calibrated using the GE Druck pressure calibrator and the deviations are found within $\pm 0.25 \%$. Fluke Temperature Scanner is calibrated using the GE DMM Voltage and found within \pm 0.1 Deg. C. $\mathrm{K}$ type thermocouples used in these experiments are also calibrated using the GE DMM Voltage system and found within $\pm 0.1 \mathrm{Deg}$. C. Mass flow through the orifice meter is calculated based on the upstream and down pressures, which are found using the pressure net scanner.

\section{COMPUTATIONAL DETAILS OF PRESENT STUDY}

Film cooling effectiveness and heat transfer coefficient data is calculated experimentally for different blowing ratios of 1.25 , $1.50,1.75$ and 2.0 for blade leading edge configurations with 15,30 and $45 \mathrm{deg}$. hole orientation angles. The same has been tried numerically using Ansys Fluent commercial software to have the comparison with the experimental data. 


\subsection{Geometry of the Computational Model}

The model consists of leading edge of gas turbine blade with the flow duct. Computational model size of $300 \times 210 \times 210$ $\mathrm{mm}$ with leading edge outer diameter of $90 \mathrm{~mm}$ and inner diameter of $70 \mathrm{~mm}$, having a row of five film cooling holes of $3 \mathrm{~mm}$ dia. with a hole pitch of $20 \mathrm{~mm}$ is generated. The generated computational model size is same for all the three models i.e. 15, 30 and $45 \mathrm{deg}$. hole orientation angle models. Computational model is prepared as per experimental test section and only half of length of the test section is taken to avoid more number of element cells and analysis running time. Computational model is prepared using solid works as shown in the Fig.5 and imported in ICEM CFD.

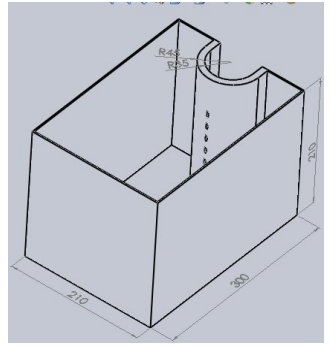

Figure 5: Geometry of the computational model

\subsection{Grid Generation}

ANSYS ICEM CFD is used to create a computational grid. The Hexa mesh is constructed for whole domain. The preprocessor, solver and Postprocessor modules are employed by ANSYS 13 Fluent. Hexa type mesh is used for main stream fluid region in order to obtain highest accuracy. And $\mathrm{O}$ grid mesh is used for the coolant flow. Blocking technique is used for easier meshing. With these, mesh quality is obtained above 0.4 and $\mathrm{y}^{+}$value of 13 is obtained near wall adjacent for the turbulence model. In total 699765 grid cells have obtained for the entire geometry. As part of Grid dependence study, Adiabatic film cooling effectiveness is calculated with higher fine mesh cells of 699765 and 1365789, both have shown the same results but, the computational time took for the 699765 cells is very less when compared to 1365789 cells. Hence, the computational model with 699765 number of cells has been chosen for this analysis. With the higher fine mesh, the $y+$ value comes lower but the computational time is becoming a very large for the convergence of solution. And as a grid dependence study, further fine mesh beyond 699765 cells does not shown the change in results. And the adiabatic film cooling effectiveness does not need the $\mathrm{Y}^{+}$value near the wall. Hence, the adiabatic film cooling effectiveness is calculated with $\mathrm{Y}+$ value of 13 with the lesser computational time.

The computational model after the meshing with grid cells is shown in the Fig.6. The film coolant hole is meshed with $\mathrm{O}$ grid technique. At the inlet and outlet coolant hole is obtained with $\mathrm{O}$ grid. Coolant holes are attached to the blade leading edge model with mesh connectivity by using splitting technique near the hole fine mesh. The coolant hole with the coolant flow meshed with $\mathrm{O}$ grid is shown in the Fig.7

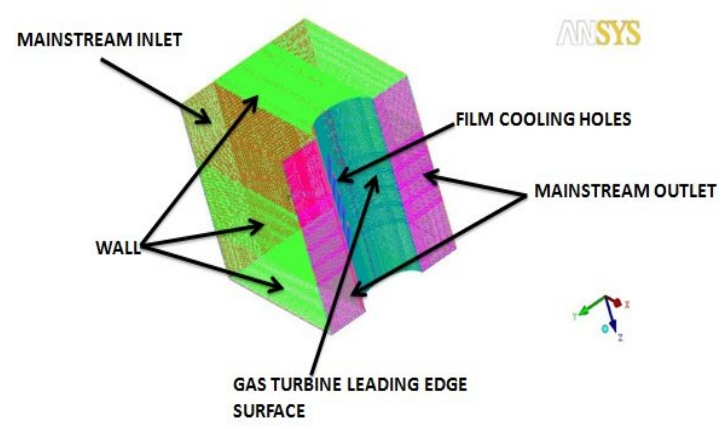

Figure 6: Grid generation of computational model
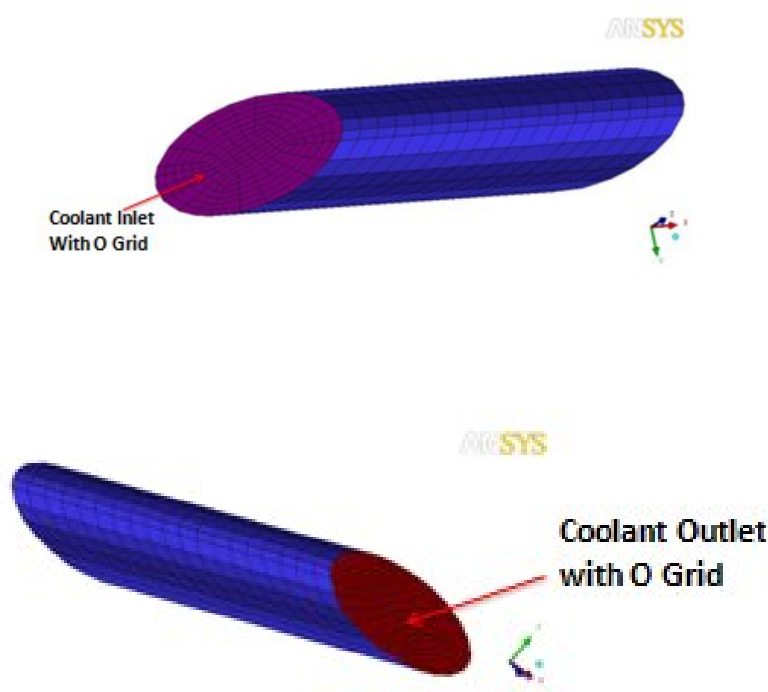

Figure 7: Grid generation of film cooling holes

\subsection{Boundary Conditions}

\begin{tabular}{|c|l|l|}
\hline SI. No. & \multicolumn{1}{|c|}{ Part } & Boundary Type \\
\hline 1 & $\begin{array}{l}\text { Main Stream Inlet } \\
\text { and Coolant Inlet }\end{array}$ & Velocity Inlet \\
\hline 2 & Main Stream Outlet & Pressure Outlet \\
\hline 3 & Coolant Outlet & Interior \\
\hline 4 & Wall & Wall \\
\hline 5 & Solid Surface & Wall \\
\hline 6 & Fluid & Fluid \\
\hline
\end{tabular}

Table 1: Boundary Conditions

The type of boundary conditions applied in all the computational models are shown in the Table 1 . The boundary condition values are used same as experimental test values, as shown in Table 2. 


\begin{tabular}{|l|c|c|l|l|}
\hline $\begin{array}{l}\text { Blowing } \\
\text { Ratio }\end{array}$ & $\begin{array}{l}\text { Mainstream } \\
\text { Temp. in k }\end{array}$ & $\begin{array}{l}\text { Coolant } \\
\text { Temp. in k }\end{array}$ & $\begin{array}{l}\text { Mainstream } \\
\text { Velcity } \\
\text { in m/sec }\end{array}$ & $\begin{array}{l}\text { Coolant } \\
\text { Velocity } \\
\text { in m/sec }\end{array}$ \\
\hline 1.25 & 300 & 243 & 20 & $\mathbf{2 0 . 2 2}$ \\
\hline 1.50 & 300 & 243 & 20 & $\mathbf{2 4 . 2 6}$ \\
\hline 1.75 & 300 & 243 & 20 & $\mathbf{2 8 . 3 1}$ \\
\hline 2.00 & 300 & 243 & 20 & $\mathbf{3 2 . 3 5}$ \\
\hline
\end{tabular}

Table 2: Experimental Test conditions

It is an unfortunate fact that no single turbulence model is universally accepted as being superior for all classes of problems. The choice of turbulence model will depend on considerations such as the physics encompassed in the flow, the level of accuracy required, the available computational resources, and the amount of time available for the simulation. As per the experimental flow physics, here the flow has a higher Reynolds number and become turbulence, hence turbulence model is chosen for the computational analysis. And, while choosing a particular $\mathrm{k}-\varepsilon$ realizable turbulence model, it has been tried with the with $\mathrm{k}-\varepsilon$ standard and $\mathrm{k}-\varepsilon$ realizable turbulence models based on literature survey and found the $\mathrm{k}-\varepsilon$ realizable turbulence model gives the better results in comparison with experimental values. Hence, the k- $\varepsilon$ realizable turbulence model is considered in this computational analysis.

\section{RESULTS AND DISCUSSION}

Film temperature and velocity contours for all the models are numerically simulated by varying the blowing ratios. By using this surface film temperature values obtained from CFD, cooling effectiveness is calculated for all the models. The temperature and velocity contours are shown in the Figs. 8 to 10 for the 15, 30 and $45 \mathrm{deg}$. models respectively. For the $15 \mathrm{deg}$ model the profiles showed the divergence in comparison to the 30 and 45 deg. models due to the main stream flow resistance for the coolant flow.
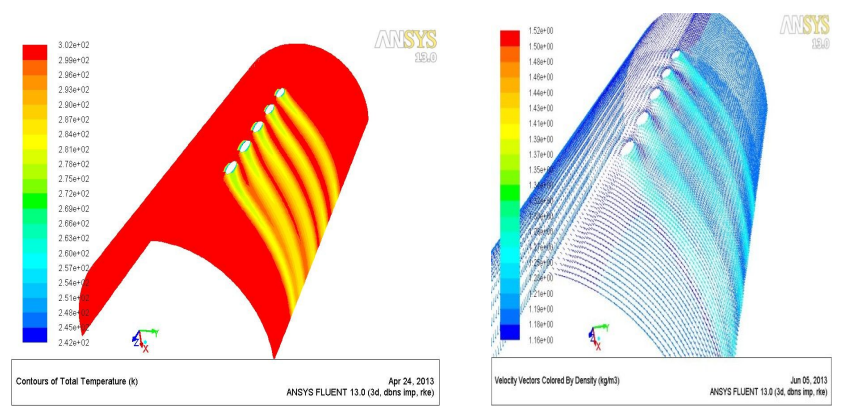

Figure 8: Temperature and velocity contours for $15 \mathrm{deg}$. cooling hole model at $\mathrm{B} . \mathrm{R}=1.25$
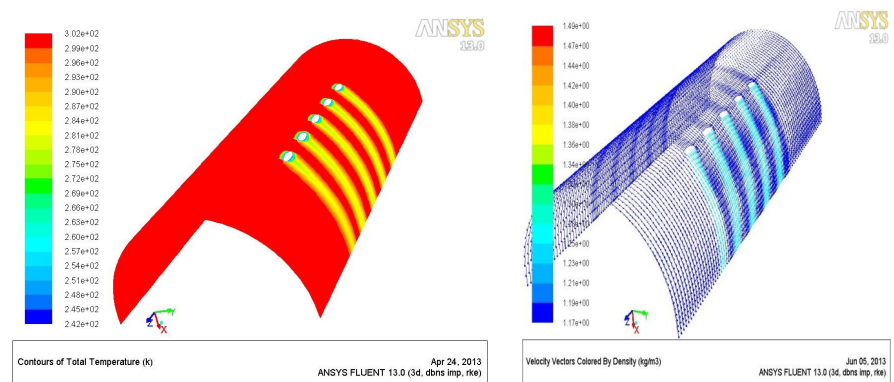

Figure 9: Temperature and velocity contours for 30deg. cooling hole model at $\mathrm{B} \cdot \mathrm{R}=1.25$
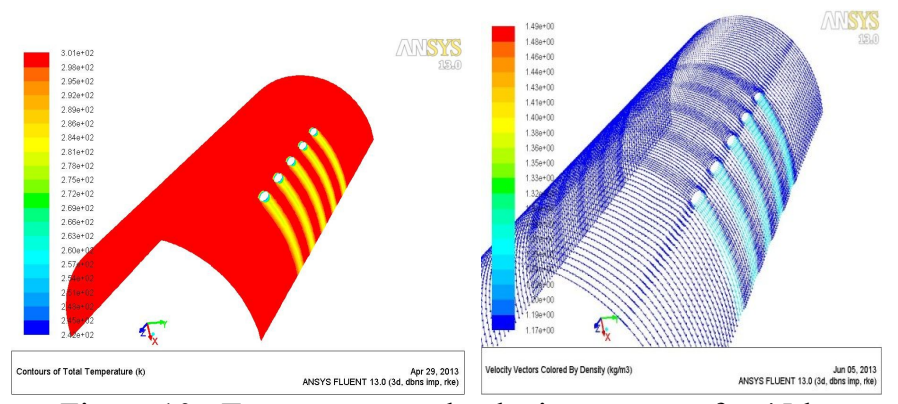

Figure 10: Temperature and velocity contours for $45 \mathrm{deg}$. cooling hole models at $\mathrm{B} \cdot \mathrm{R}=1.25$

Film cooling effectiveness and heat transfer coefficient values are evaluated experimentally for all the three leading edge models with 15, 30 and $45 \mathrm{deg}$. hole orientation angles. The typical experimental film cooling effectiveness results along the stream wise direction at the blowing ratios of 1.25 and 1.5 are shown in the Figs. 11 and 12.The experimental data shows the increase in cooling effectiveness with the increase in hole orientation angle from the stagnation line. The higher cooling effectiveness is observed for the $45 \mathrm{deg}$. blade model due to the less flow resistance from the main stream flow. And in general, with the increase in blowing ratio the cooling effectiveness increases as observed from the experimental data. From the experimental data, the effect of increase in cooling effectiveness is observed maximum at the blowing ratio of 1.5 for the 15 and $30 \mathrm{deg}$. angle models. And for the $45 \mathrm{deg}$. angle model the cooling effectiveness is observed maximum at the blowing ratio of 1.75. The typical experimentally evaluated cooling effectiveness for the $45 \mathrm{deg}$. model is shown in the Fig. 13. Stream wise direction is considered as the direction parallel to the main flow direction where as the span wise direction is the direction perpendicular to the flow direction along the row of holes. 


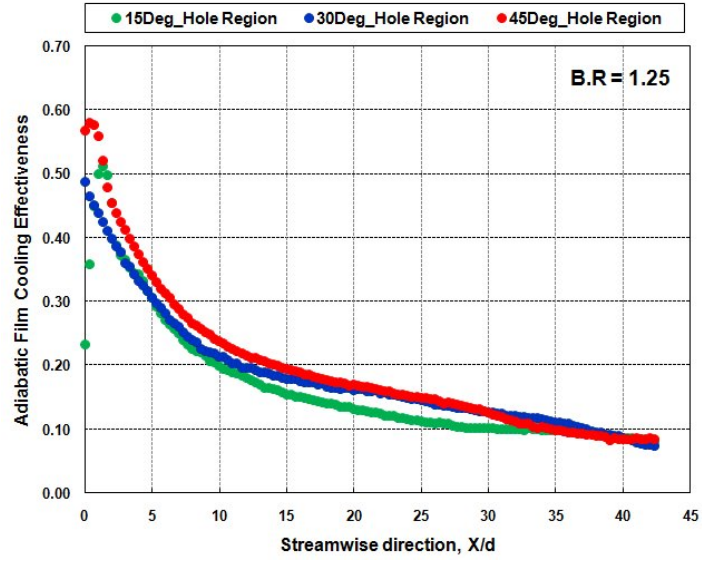

Figure 11: Experimentally evaluated adiabatic film cooling effectiveness at the blowing ratio of 1.25 for the 15,30 and 45deg. angle models.

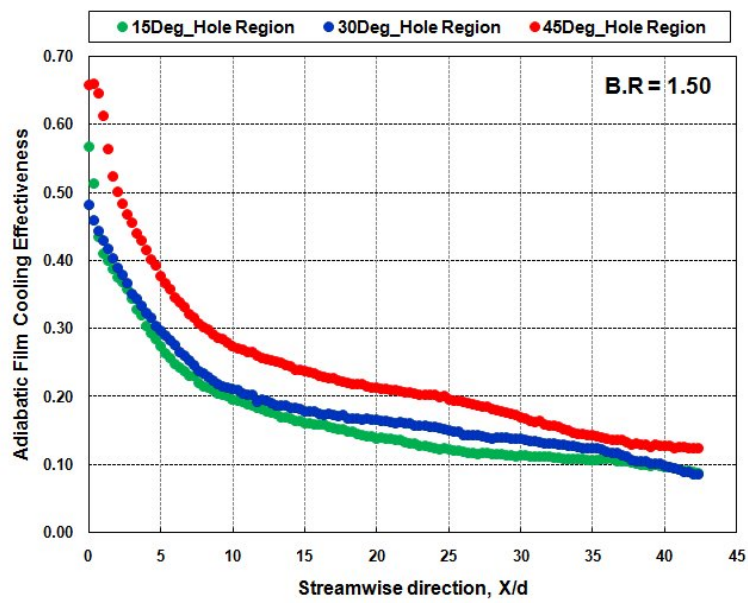

Figure 12: Experimentally evaluated adiabatic film cooling effectiveness at the blowing ratio of 1.50 for the 15,30 and $45 \mathrm{deg}$. angle models.

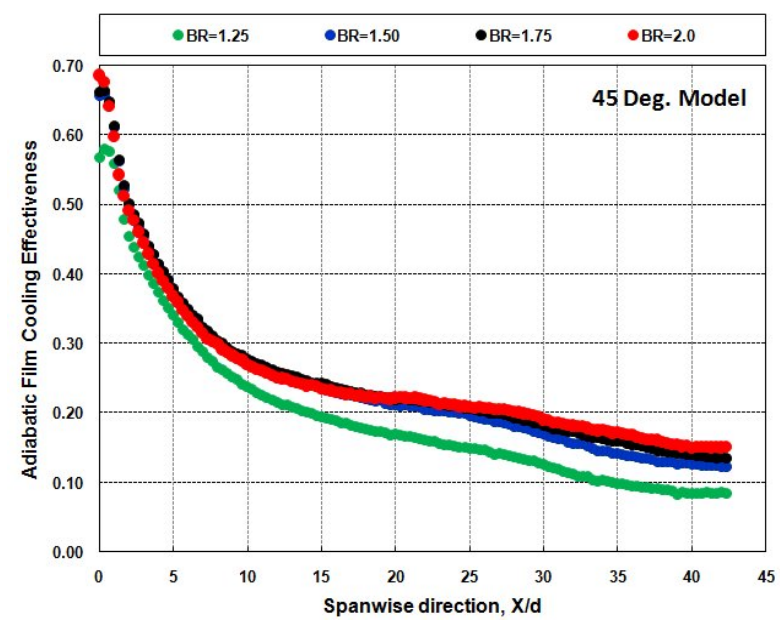

Figure 13: Experimentally evaluated adiabatic film cooling effectiveness downstream of the hole region for $45 \mathrm{deg}$. model.
The heat transfer coefficient increases with the increase in hole orientation angle from the stagnation line and it is shown higher value for $45 \mathrm{deg}$. model among the considered three models. The heat transfer coefficient is shown higher for the $45 \mathrm{deg}$. model because the holes are located at the downstream of the flow hence; there is no flow resistance from mainstream flow to the coolant flow. The effect of hole orientation angle on the heat transfer coefficient is shown in the Fig. 14.

Heat transfer coefficient is calculated for 15, 30 and 45 deg film cooling hole of gas turbine blade leading edge models for a constant heat flux supplying to the plate. From the experiments, it is found that the heat transfer coefficient increases with the increase in blowing ratios for 15,30 and $45 \mathrm{deg}$ model. The effect of blowing ratio showed not much variation on the heat transfer coefficient for the 45 deg. model. The Fig. 15 Shows the HTC values for the $45 \mathrm{deg}$. model with the blowing ratio from 1.25 to 2.0 , up to 1.75 the HTC increases after that HTC found remains same. Whereas the 15 and $30 \mathrm{deg}$. angle models shows the increase in HTC with the increase in blowing ratio in the considered range.

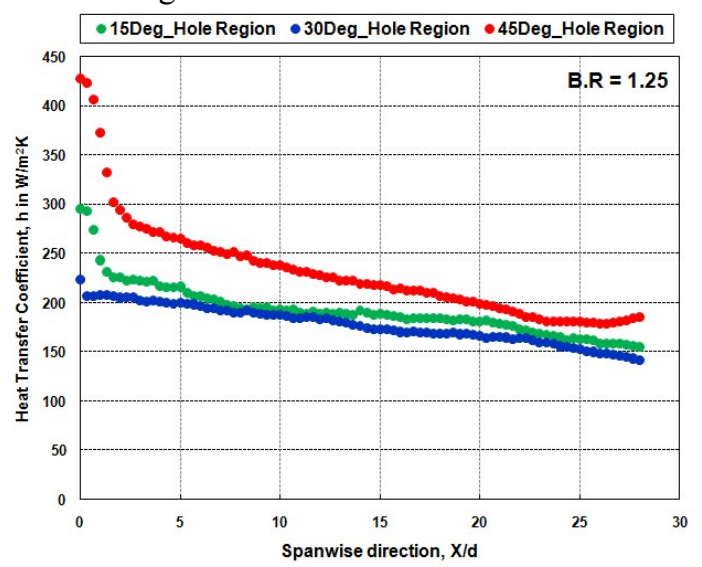

Figure 14: Experimentally evaluated heat transfer coefficient at the blowing ratio of 1.25 for the 15,30 and $45 \mathrm{deg}$. hole orientation angle models.

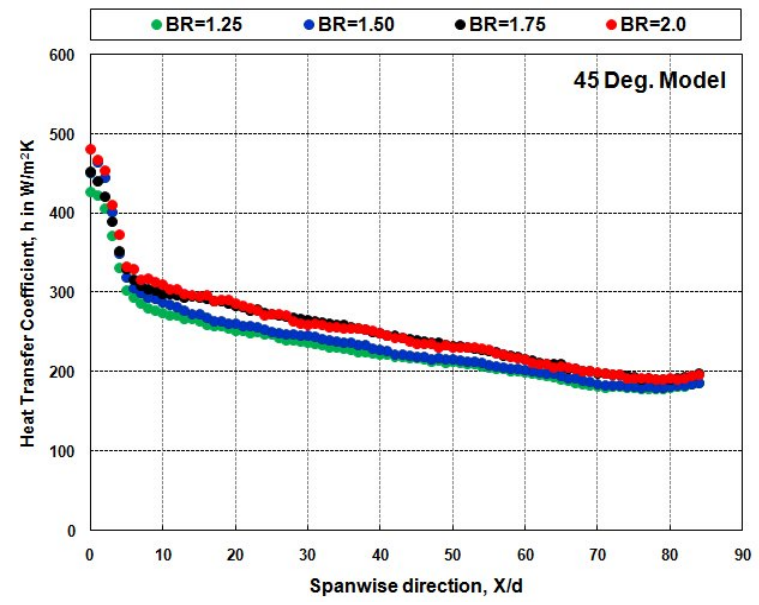

Figure 15: Experimentally evaluated heat transfer coefficient downstream hole region for $45 \mathrm{deg}$. model. 
A typical thermal images captured by infra red camera of the film cooling effectiveness and heat transfer coefficient at the blowing ratio of 1.5 for the $30 \mathrm{Deg}$. model are shown in the Fig.16.
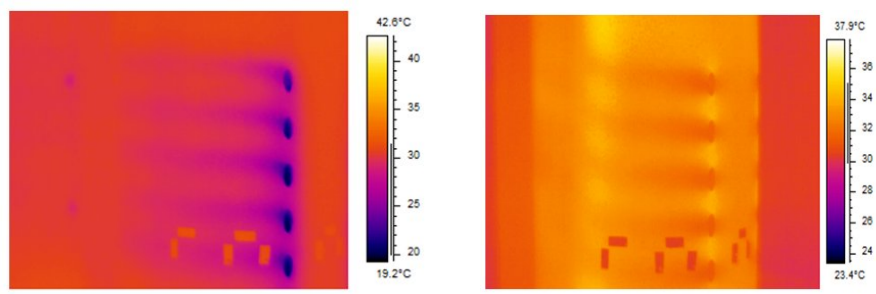

Figure 16: Infra red thermal image for the film cooling effectiveness and heat transfer coefficient of $30 \mathrm{deg}$. angle blade leading edge model at the blowing ratio of 1.50

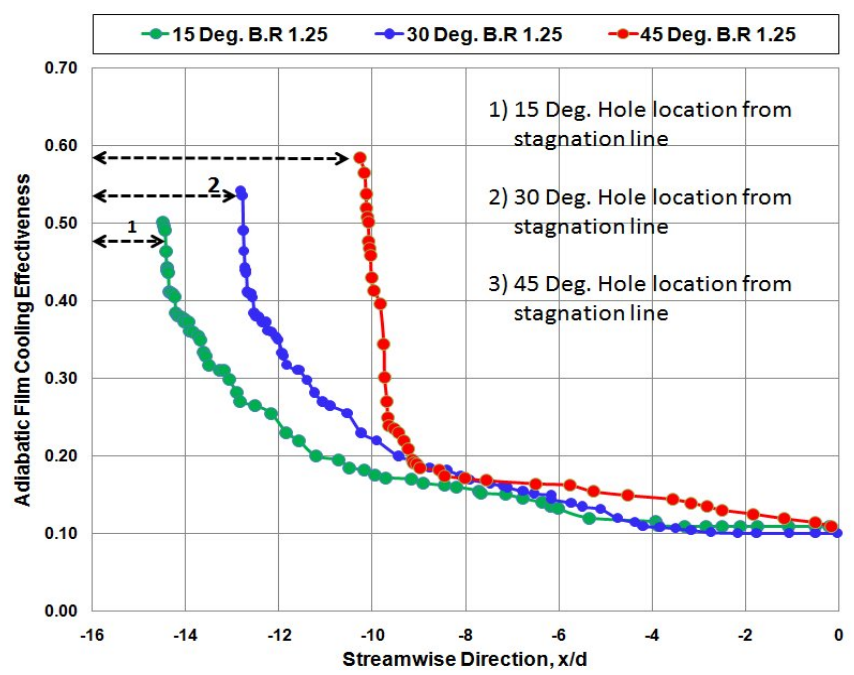

Figure 17: Numerically evaluated (CFD) adiabatic film cooling effectiveness in the stream wise direction at the downstream of holes for the 15, 30 and $45 \mathrm{deg}$. models at B. $\mathrm{R}=1.25$

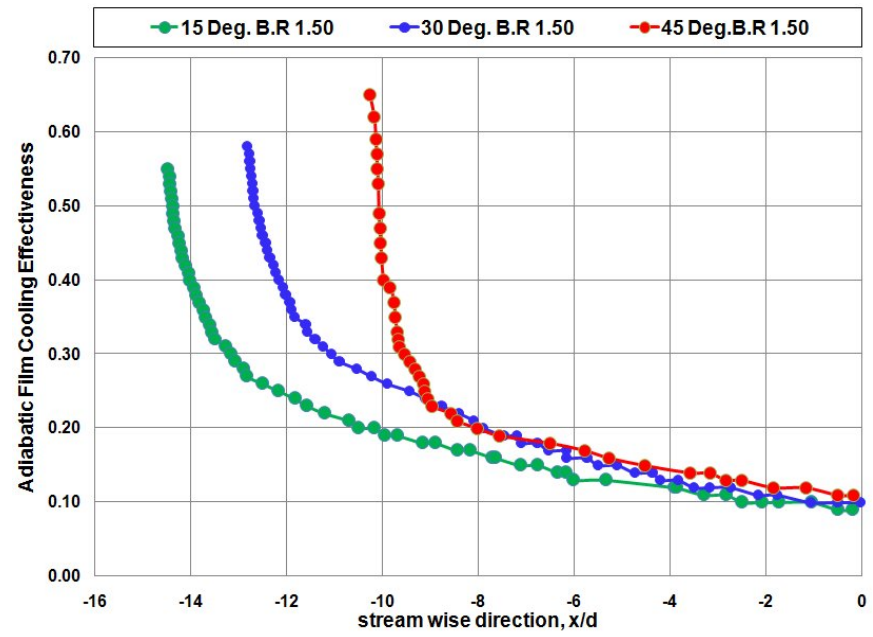

Figure 18: Numerically evaluated (CFD) adiabatic film cooling effectiveness in the streamwise direction at the downstream of holes for the 15, 30 and 45 deg. models at B.R $=1.50$
In numerical (CFD) evaluation, the adiabatic film cooling effectiveness is calculated for the 15, 30 and $45 \mathrm{deg}$. angle models separately, Film cooling effectiveness is found downstream of the holes on each model separately and plotted in the single graph for the comparative analysis.

Fig. 17 and 18 shows the numerically evaluated adiabatic film cooling effectiveness at B.R 1.25 and 1.5 in streamwise direction at the downstream of holes. These results shown the increase in cooling effectiveness with the increasing hole orientation angle and it is observed higher value for the $45 \mathrm{deg}$. angle model among the considered models.

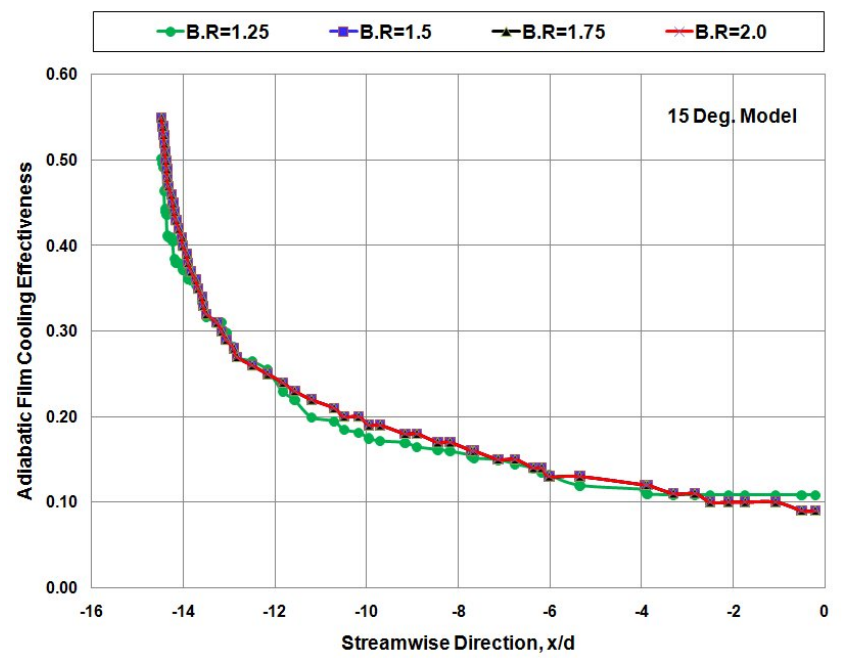

Figure 19 (a): Numerically evaluated adiabatic film cooling effectiveness for $15 \mathrm{deg}$. angle model. at the blowing ratios of $1.25,1.5,1.75$ and 2.0

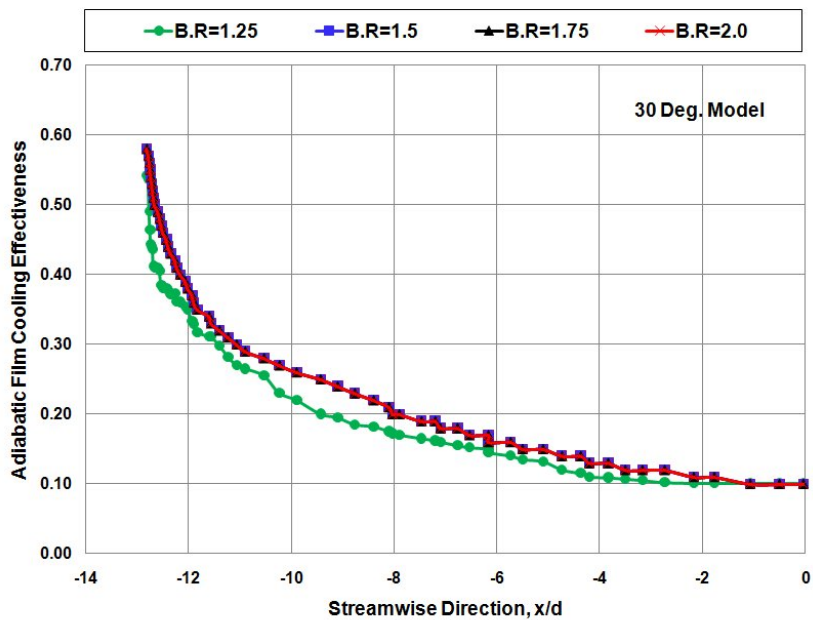

Figure 19 (b): Numerically evaluated adiabatic film cooling effectiveness for $30 \mathrm{deg}$. angle model. at the blowing ratios of $1.25,1.5,1.75$ and 2.0 


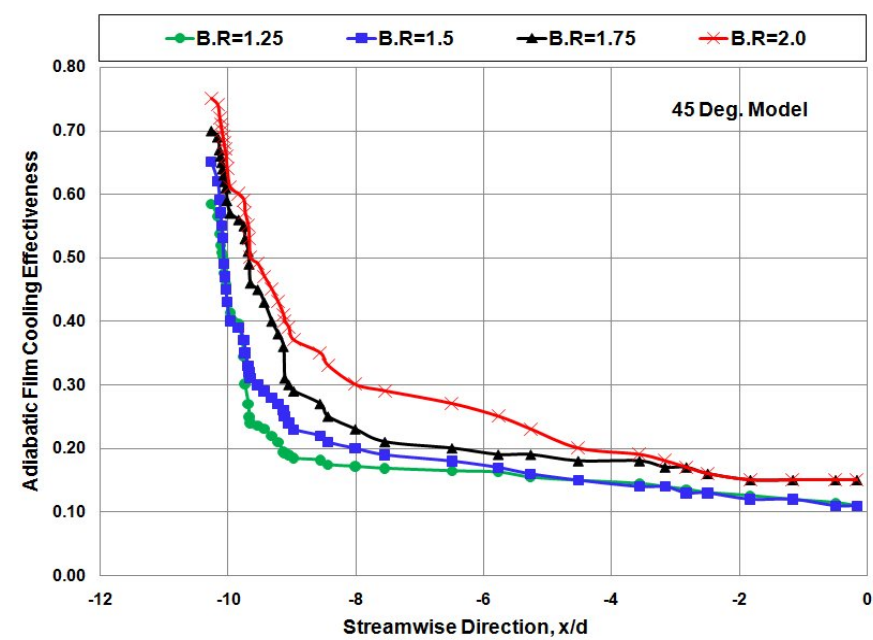

Figure 19 (c): Numerically evaluated adiabatic film cooling effectiveness for $45 \mathrm{deg}$. angle model. at the blowing ratios of $1.25,1.5,1.75$ and 2.0

Fig. 19 (a), (b) and (c) shows the numerically evaluated adiabatic film cooling effectiveness for the 15, 30 and $45 \mathrm{deg}$. angle hole models respectively at the blowing ratios of 1.25 , $1.5,1.75$ and 2.0 in streamwise direction at the downstream of holes.

In numerical (CFD) evaluation, the adiabatic film cooling effectiveness is calculated for the 15, 30 and $45 \mathrm{deg}$. angle models separately, the film effectiveness shows the increase with the increasing blowing ratio, where as $45 \mathrm{deg}$. angle model gives higher film effectiveness when compared to 15 and 30 deg. angle models. Film cooling effectiveness is found downstream of the holes on each model separately and plotted in the single graph for the comparative analysis.

In general, CFD showed the increase in film cooling effectiveness with increase in blowing ratio. From the Figs. 19 (a) and (b), cooling effectiveness shown the increase with the increasing blowing ratio up to 1.50 for the 15 and $30 \mathrm{deg}$. angle models and for the blowing ratio above 1.50 there is no increase in cooling effectiveness for these models. From the Fig. 19 (c ), cooling effectiveness showed the increase with the increasing blowing ratio for the $45 \mathrm{deg}$. angle model among the considered blowing ratios.

The similar trends in the increase in the film cooling effectiveness have been found by both experimentally and numerically.

\section{CONCLUSIONS}

The present study deals with experimental and numerical investigation of adiabatic film cooling effectiveness and heat transfer coefficient for gas turbine blade leading edge models with different cooling hole locations from the stagnation line i.e. 15,30 and $45 \mathrm{deg}$. hole orientation angles. From the experimental evaluation, the cooling effectiveness shown the increase with the increasing hole orientation angle and it is observed higher value for the $45 \mathrm{deg}$. angle model among the considered models. And the cooling effectiveness shown the increase with the increasing blowing ratio up to 1.50 for the 15 and 30 deg. angle models and for the blowing ratio above 1.50 there is no increase in cooling effectiveness for these models. And the cooling effectiveness showed the increase with the increasing blowing ratio for the $45 \mathrm{deg}$. angle model among the considered blowing ratios.

From the experiments, it is found that the heat transfer coefficient increases with the increase in hole orientation angle as it shown higher at $45 \mathrm{deg}$. angle model among the considered models. And it is found that the heat transfer coefficient increases with the increase in blowing ratios for 15,30 and 45 deg. angle models. The effect of blowing ratio showed not much variation on the heat transfer coefficient for the $45 \mathrm{deg}$. model above the blowing ratio of 1.75 , whereas the 15 and $30 \mathrm{deg}$. angle models shown the increase in HTC with the increase in blowing ratio in the considered range.

From numerical evaluation, film effectiveness shows increase with increasing blowing ratio and the values shown nearer to the experimental values with the same flow patterns. And among the two considered turbulent solver models of k-epsilon standard and k-epsilon realizable, the k-epsilon realizable turbulence model showed the suitable model as per the experimental flow conditions.

From both the experiments and numerical analysis, it is found that hole orientation angle and the blowing ratio are the major parameters affecting both the film cooling effectiveness and heat transfer coefficient. Hence, the optimized hole orientation angles and the blowing ratios are to be placed for the good design of gas turbine blades.

\section{Nomenclature}

$\begin{array}{lll}\text { A } & - & \text { Area, } \mathrm{m}^{2} \\ \text { B.R } & - & \text { Blowing Ratio } \\ \text { D.R } & - & \text { Density Ratio } \\ \text { D } & - & \text { Diameter of the leading edge model, mm } \\ \text { d } & - & \text { Diameter of Film cooling Hole, } \mathrm{mm} \\ \text { deg. } & - & \text { Degrees } \\ \text { h } & - & \text { Heat transfer coefficient, W/m } \mathrm{m}^{2} \mathrm{k} \\ \mathrm{I} & - & \text { Current in Amperes } \\ \text { Fig. } & - & \text { Figure } \\ \text { M } & - & \text { Mass Flow, kg/s } \\ \text { P } & - & \text { Pressure, Pa } \\ \text { Q } & - & \text { Heat Input, Watts } \\ \text { q } & - & \text { Net Heat Flux the Foil Surface in W/m } \\ \text { T } & - & \text { Temperature, } \mathrm{k} \\ \text { V } & - & \text { Voltage in Volts } \\ \text { v } & - & \text { Velocity, m/s }\end{array}$

\section{Greek Symbols}

$\eta \quad$ - $\quad$ Adiabatic film Cooling Effectiveness

$\rho \quad$ - Density 


\section{Subscripts}

$\begin{array}{lll}\mathrm{c} & - & \text { Coolant } \\ \mathrm{f} & - & \text { Film } \\ \text { gen } & - & \text { Generated } \\ \text { Loss } & - & \text { Local Heat Loss } \\ \mathrm{m} & - & \text { Mainstream } \\ \mathrm{w} & - & \text { Wall }\end{array}$

\section{ACKNOWLEDGMENTS}

The authors wish to thank Head, Propulsion Division and Director, NAL, Bangalore for permitting this work to be done at NAL. The authors wish to thank Mr. Manjunath P. and Dr. Rajendran R., Dy. Heads, Propulsion Division for their valuable suggestions to carry out this work. The authors also thank to Mr. Maria Arockiam and Mr. Sanmuganantham for their help in fabrication, assembling and assisting in the experiments. Authors would like to thank all the members and to all others who have directly or indirectly helped us in carrying out this work.

\section{REFERENCES}

1) Shuye Teng and Je-Chin Han "Effect of Film-Hole shape on Turbine Blade Heat Transfer Coefficient Distribution" American Institute of Aeronautics and Astronautics 20001035.

2) Ken-ichi Funazaki, Hirokazu Kawabata and Yoji Okita "Free-Stream Turbulence Effects on Leading Edge Film Cooling" International Journal of Gas Turbine, Propulsion and Power System. February 2012, Volume 4, Number 1.

3) May Kyu Kyu Soe, Ding Shui Ting, and Wu Hong "Analysis of Film Cooling Effectiveness on Antivortex Hole" School of Jet Propulsion, Beijing University of Aeronautics and Astronautics Beijing, China.

4) James L. Rutledge, Paui L.King, and Richard Rivir "CFD Predictions of Pulsed Film Cooling Heat Flux on A Turbine Blade Leading Edge" Proceedings of IMECE2008, 2008 ASME International Mechanical Engineering Congress and
Exposition October 31 November 6, 2008, Boston, Massachusetts,USA

5) JE-Chin Han and Srinath Ekkad "Recent Development In Turbine Blade Film Cooling" International Journal of Rotating Machinery 2001, Vol 7, No 1, pp 21-40

6) Youn J. Kim, S.M.Kim "Influence of Shaped Injection Hole on Turbine Blade Leading Edge Film Cooling" International Journal of Heat and Mass Transfer 47(2004) 245-256.

7) Ali Rozati, Danesh K. Tafti "Effect of Coolant -Mainstream Blowing Ratio on Leading Edge Film Cooling Flow and Heat Transfer-Les Investigation" International Journal of Heat and Fluid Flow 29(2008) 857-873.

8) Cruse,M.W., Yuki U. and Bogard D.G. "Investigation of various parametric influences on leading edge film cooling" ASME Paper 97-GT-296 ( 1997)

9) Albert.J.E, Bogard.D.G and Frank Cunha:“Adiabatic and overall effectiveness for a film cooled blade", ASME Turbo Expo- Power for Land, Sea and Air, Vienna, Austria, GT2004-53998 (2004).

10) Gartshore, I., Salcudean, M., McLean, I., Zhang, K.“An experimental study of film cooling effectiveness near the leading edge of a turbine blade". ASME Journal of Turbomachinery, 116, 71-79(1994)

11) Eckert, E.R.G.,Simon,T.W. and Graskow B.R.: "Exploration of the influence of heat conduction on the temperature distribution in turbine blades", Paper No. HTD-Vol350, National Heat transfer Conference, Vol.12, pp 199-211 ASME (1997)

12) S. F. Shaker, M.Z. Abdullah, M. A. Mujeebu, K.A. Ahmad And M.K. Abdullah "Study on The Effect of Number of Film Cooling Rows on The Thermal Performance of Gas Turbine Blade" Journal of Thermal Science and Technology, ISSN 1300-3615 (2012). 